\title{
CIUDAD TEXTUAL: \\ EL REFERENTE URBANO EN TRES NOVELAS \\ DE LA DÉCADA DEL CUARENTA
}

POR

Ángel Gustavo InFante

Hay un laberinto de las calles que sólo la aventura personal puede penetrar y un laberinto de los signos que sólo la inteligencia razonante puede descifrar, encontrando su origen. Ángel Rama

\section{Caracas 1940-1950}

\section{Ciudad visible}

Los cambios substanciales que experimenta la capital en la década del cuarenta nos hacen pensar que en ese período podemos ubicar las claves para entender la fisonomía y fisiología del cuerpo urbano actual.

Si la fundación creó una sociedad expresada en un rostro cuadriculado, uniforme, casi cuatrocientos años después se acentúa el quiebre, la escisión, de aquel rostro y aquella sociedad, a tal punto que el cuerpo en permanente desarrollo presenta un cuadro desconcertante.

La ciudad es un pequeño emporio, punto intermedio de transacciones que aceleran su deformación. La muerte de Juan Vicente Gómez permite cierta apertura y el gran feudo unifamiliar da los primeros pasos hacia la urbanización.

Bajo la administración del general Isaías Medina Angarita (1941-1945) se inicia la construcción de El Silencio. Éste es, quizá, el primer signo de la modernidad. La escala humana contemporánea se nos presenta en el diseño socio-estético de Carlos Raúl Villanueva.

Hacia 1945 la capital tiene sólo tres accesos principales: desde el puerto de La Guaira, los que vienen de ultramar suben en los últimos vagones del ferrocarril o en automóviles que deben desplazarse con igual lentitud por una vía estrecha, paralela a los rieles; desde la región centro-occidental, la vieja carretera Panamericana pasa por Los Teques y desemboca en el pueblo de Antímano; y, finalmente, desde el oriente del país, el camino de Guarenas despide al viajero en la villa de Petare.

El Norte de Caracas se prolonga en viviendas diversas. En la parroquia San José, como en otras parroquias suburbanas, habita la mayoría de la mano de obra que los constructores extranjeros emplean. 
La actividad artística tiene un centro, construido a finales de la década anterior: el Museo de Bellas Artes. Otras obras perviven desde el siglo XIX: el Palacio de Miraflores, sueño irrealizado de Joaquín Crespo; toda la cuadra encabezada por la ceiba de San Francisco y más allá, después del arco de triunfo de La Federación, donde se corona la herencia guzmancista con el gran monumento de El Calvario.

La Cárcel del Obispo, después de la demolición de La Rotunda, es el centro de la "actividad política". Durante los primeros cinco años de la década hospeda a los jóvenes estudiantes que pronto protagonizarán la historia política del país.

Después de la Revolución del 18 de octubre de 1945, se observa cierta parálisis en el desarrollo fisonómico. El accidentado lustro en que Betancourt, Gallegos y Chalbaud, entre otros, comparten y se suceden en la primera magistratura.

Los superbloques, las autopistas, la ciudad universitaria, entre otras obras concluidas o inconclusas - como El Helicoide - pertenecen a décadas posteriores.

\section{Ciudad invisible}

La red visualmente imperceptible que crean las relaciones de significación y los procesos de comunicación al establecerse, hace la base ideológica, ideal y conceptual de la ciudad visible.

Estos productos supraestructurales que conforman el proceso de la otra ciudad, la ciudad invisible, se expresan, grosso modo, en dos tipos de discurso: el discurso oficial y los discursos alternos.

El primero estaría constituido por las categorías ideológicas propuestas por la voz oficial encargada del control, custodia y administración del territorio, su población y riquezas.

En el segundo tipo podríamos ubicar a los discursos "libres" que enfrentan y se contraponen a los oficiales (o los recrean y reproducen). Estos, no exentos de ciertas dosis ideológicas, se mueven entre la comunicación, la proposición conceptual, la elaboración estética y ficcional.

Ambos tipos de discurso expresan la fisiología del cuerpo urbano, son los significantes de la ciudad visible. La otra, la ciudad invisible, es la consecuencia formal de la primera: la fisonomía, unión de cabeza, rostro, cuerpo, extremidades. Es el espacio del hombre, donde construye o consigue su hábitat.

Las funciones de la ciudad visible no se cumplen aisladamente, se inscriben en el macroorganismo continental que, más que expulsar, digiere el discurso neocolonial de las metrópolis.

Ángel Rama señala el cumplimiento de un primer período "nacionalista" entre 19111930 y un segundo "populista", desprendido desde allí hasta 1972, "teleguiado por fuerzas internacionales" $(1984,114)$.

Durante el período nacionalista, según Vieira de Mello, predominó la noción de "país nuevo". Se trata del país que "todavía no había podido realizarse pero que se atribuía a sí mismo grandes posibilidades de progreso futuro". Después de 1930, en el período populista, predominará la noción de "país subdesarrollado" (Antonio Cándido 1977, 335). 
La década del cuarenta es el lapso de transición de una a otra noción. Después de Gómez sobreviven los rasgos del "país nuevo". Diez años más tarde resulta difícil negar la insistencia de esta categoría ideológica, prolongada por la precisa observación de Mariano Picón Salas: en 1936 Venezuela entra al siglo XX.

Entre 1940-1950 el discurso político se debate y alterna entre los patrones militares y las propuestas hacia la apertura democrática. Se fundan los partidos políticos Acción Democrática (1941) y Copei (1946). Se legaliza el Partido Comunista de Venezuela (1945). Es la época de efervescencia del movimiento estudiantil encabezado por Jóvito Villalba y Rómulo Betancourt, los años dorados de $\mathrm{AD}$ como proyecto de izquierda impulsado por Leonardo Ruíz Pineda, entre otros, y el surgimiento de la esperanza socialcristiana conducida por el joven Rafael Caldera.

El escritor-presidente Rómulo Gallegos protagoniza un brevísimo lapso como mandatario: febrero a noviembre de 1948. Lo derroca una junta militar comandada por Carlos Delgado Chalbaud y Marcos Pérez Jiménez, que terminará con el asesinato del primero y la entronización del segundo.

Los discursos alternos, específicamente los estéticos, bajo la noción de país nuevo y cercanos a la crisis del subdesarrollo, exaltan (o denigran) los valores regionales en un intento por mostrar las riquezas (o miserias) "vírgenes" de la promesa nacional.

La exuberante vegetación de la "Tierra Prometida" en Mi padre el inmigrante, de Vicente Gerbasi; las mulatas robustas que transportan frutas en las esculturas de Francisco Narváez; los campesinos descalzos y desorientados en las pinturas de César Rengifo y Gabriel Bracho; el pintoresquismo, la denuncia social y la identidad llevadas al cine en films como Romance aragüeño, Juan de la calle, Dona Bárbara, Alma llanera y Barlovento; ilustran la insistencia en mostrar el brillo y las sombras de la región.

Los ejemplos anteriores, no obstante, están más cercanos al llamado "regionalismo pintoresco", propio de la "fase de conciencia exaltada de país nuevo" que al "regionalismo problemático" en la "fase de preconciencia del subdesarrollo" (Cándido 1977, 350-351). Éste lo encontramos expresado con mayor propiedad en la novela.

El corpus novelístico nos presenta un catálogo de lugares problematizados. Se evidencia cierto ánimo por mostrar el país con sus respectivas miserias y riquezas.

De esta manera, encontramos a la región central referida en Ya en el otoño de Mercedes López León, Rebeldia de Lucila Palacios, Fronteras de Juan Oropesa y Nochebuena negra de Juan Pablo Sojo.

El debate sobre el país y su destino cuenta con varias páginas en estos textos. Decadencia y atraso son los conceptos que mejor manejan los narradores de la época en textos que parecen estar más cerca del tratado sociológico que de la novela.

La región occidental es, quizá, la de mayor representación. Sus pueblos y pequeñas ciudades están "ficcionalizadas" en Mana Juana de Joaquín Delgado, Uno de los de Venancio de Alejandro García Maldonado, Sobre la misma tierra de Rómulo Gallegos, Venganza o el bastardo de Víctor Paiva y en Viaje al amanecer de Mariano Picón Salas.

La región oriental está presente en Dámaso Velásquez de Antonio Arráiz. Y, finalmente, la región de los llanos en El forastero de Gallegos.

El corpus novelístico en cuestión refiere el período Castro-Gómez (1900-1935) y es producido entre 1920 y 1936. Las obras se publican a partir de 1940. Salvo algunas 
excepciones, los autores utilizan la forma novela para analizar, mostrar y denunciar la realidad del país. Les interesa el reflejo fiel del "objeto real", no la ficcionalización del entorno que constituye el espacio referencial.

Por esta razón hemos decidido estudiar el referente urbano en tres novelas postgomecistas. Las obras de Guillermo Meneses, José Fabbiani Ruiz y Andrés MariñoPalacio, si bien reciben las secuelas del régimen, demuestran, no obstante, una factura y un espectro referencial que las anexa a la producción narrativa de la segunda mitad del siglo.

De estos libros tomaremos el "medio en que se desarrollan las acciones". Nuestro objetivo es definir el significado de ciudad. De modo que ésta no sea sólo el suelo ficcional sino más bien el espacio significante que revele las concepciones urbanas del hablante básico y su relación interdiscursiva, hablante poético, con el "objeto real" o cuerpo urbano contextual, fusión de ciudad visible e invisible.

\section{CIUDAD TEXTUAL: REFERENTE URBANO}

\section{El reflejo de la ciudad y la ciudad del texto}

Para definir con mayor precisión lo que hemos denominado ciudad textual, es necesario hacer un primer deslinde entre el reflejo de la ciudad visible y la ciudad del texto.

El reflejo es el dibujo con palabras que permiten la silueta fiel del cuerpo urbano concreto y, en su condición de copia, mantiene una relación de dependencia con el objeto.

La ciudad del texto, en cambio, guarda una relación de interdependencia con el "objeto real" (la ciudad en sí), pero sólo es posible entender esta relación a través del "interpretante" que convierte al signo urbano textual en unidad ideológico-cultural.

La interdependencia reside en esa especie de diálogo bilateral mediante el cual se va construyendo la imagen urbana dentro del texto. Es decir, la ciudad ficcionalizada oye e interpreta a la ciudad real, pero no necesariamente ha de reproducirla (éste sería el nivel del reflejo), constituye más bien un modo de discurso fisiológico.

La ciudad del texto es, en fin, la referida por el texto, la que allí vive, la ciudad textual, cuyo cuerpo es exclusivamente discursivo. Es el elemento que hemos tomado como referente para nuestro estudio, basándonos en las orientaciones metodológicas de Umberto Eco (1976) y Thomas Lewis (1980).

\section{El texto y la ciudad}

Desde el siglo XIX hasta 1950, aproximadamente, en el tratamiento del espacio urbano se cumple una constante: la capital como centro rector o puesto de mando en contraposición a la barbarie rural.

Así lo manifiestan narradores como Manuel Vicente Romerogarcía y Rómulo Gallegos. Varios nombres se ubican en este cuadro que propone la tesis civilizadora desde la capital. El campo puede estar incluido en las cercanías como trasfondo, pero así como representa el lugar puro, incontaminado, será también el ámbito ignaro, marginado de las decisiones que definirán la vida del país. 
En Todo un pueblo (1899) de Miguel Eduardo Pardo, e Ídolos rotos (1901) de Manuel Díaz Rodríguez, en cambio, el debate se desarrolla a intramuros para definir el espacio urbano y comprenderlo en su autonomía. Ya entrado el siglo esto mismo ocurre en varias novelas que nos conducen al período y a las obras de estudio: en Campeones (1939), Mar de leva (1941) y Los alegres desahuciados (1948), dentro de los límites de la ciudad en transformación podemos apreciar la correlación entre los procesos textual y urbano, para obtener el significado de Caracas y las concepciones en torno a la urbe.

\section{CAMPEONES: FIESTA Y ABYECCIÓN}

\section{Primeros signos de la urbanización}

En dos escenarios se desenvuelven los "campeones" de Guillermo Meneses: el espacio ficcionalizado de La Guaira y el de Caracas.

El primero es un lugar muy particular. Su fisonomía representa a un poblado costeño colonial y su fisiología sugiere un punto intermedio entre ciudades.

El segundo - que se convertirá en primero porque va a constituir una especie de nudo espacial del texto - es la capital subdesarrollada, definida paradójicamente por la actividad en las zonas suburbanas.

Desde Catia la Mar hasta Naiguatá, la larga costa guaireña es el corredor de los amigos adolescentes Teodoro Guillén, José Luis Monzón, Luciano Guánchez y Ramón Camacho.

Ubicado entre el puerto y la capital es un espacio de transacciones que respira, por momentos, aires cosmopolitas de ultramar en aromas y marcas que se desvanecen tras los vagones del ferrocarril vía Caracas.

Los alrededores del puerto son, apenas, rincones anexos a la ciudad, pasivos, graciosos, con ritmos de vida diferentes al del aparato portuario y sus procesos administrativos, con reuniones hogareñas al atardecer, lugares adecuados para el "sano esparcimiento" que unen al signo natural con el rural y urbano.

Más allá del cuadro central encabezado por la plaza y la iglesia, trepando las calles empedradas se hallan las casas "destrozadas" de los jóvenes protagonistas en el "barrio mísero" de calles "pendientes y rotas" con "acre olor a pobreza" (138) en permanente contraste con las anchas y encaladas casas.

En este ambiente habita la mano de obra que habrá de producir los primeros signos urbanos. A través de sus oficios, la construcción de viviendas y el deporte, harán realidad un fragmento visible de la ciudad.

Luciano (obrero), Ramón (boxeador), Dimas Guillén (albañil) y Teodoro (pítcher), ya no son los típicos personajes rurales que labran la tierra: labran, esta vez, la urbanización.

Otros personajes adelantan fisonomía y discurso urbanos: el "patiquín" Luisito Diez, dueño del club (ultra-urbano) "Nueva York" y Margot y Belén, mejor descritos por su indumentaria y automóviles (se desplazan en sendos "roadster"), caracterizan la frivolidad metropolitana (131 y 156).

El cuerpo de la ciudad muestra el mismo contraste clasista del primer escenario. Entre el rostro y las extremidades existen rasgos irreconciliables: sólo hay brillo y limpieza en la plaza Bolívar, el resto, donde van a habitar los nuevos ciudadanos, estará invadido por la inmundicia, la miseria, la sordidez. 
En la capital, el poder y la clase están representados por el doctor Pedrito Fajardo o Fajardito, el apoderado del boxeador Ramón Camacho. Es la contraparte del otrora apoderado del pítcher Guillén, el patiquín Luisito Diez. Ellos hacen la utopía ciudadana, viven las mejores expresiones del cuerpo urbano.

Otros elementos que constituyen la fisonomía del espacio urbano ilustran a la vez el pasado rural: por una esquina aparece un "coche viejo, arrastrado por dos caballos flacos y perezosos" (201), una casa de vecindad en el callejón Rivero, donde retorna a vivir el viejo Dimas y su hija Pura Guillén, la mujer de Luciano, mantiene el mismo "zaguán oscuro, húmedo, hediondo a moho" $\mathrm{y}$ "en el patio de tierra roja, rodeado por la acera encementada, picotean las gallinas ..." (218).

El rostro de la ciudad se transforma en la visión del hablante poético: Caracas es, desde el primer escenario, la tierra prometida, el sitio del progreso: una utopía.

Una quimera, desde el segundo. Rostro apreciado in situ bajo la alegría de la fiesta.

De allí "el espanto" de Luciano, que "apenas pudo reconocer las calles empolvadas, transitadas por gente que iba de prisa" (206), la única vez que observó el rostro sin las caretas del béisbol ni el antifaz del carnaval.

\section{Fiesta y abyección}

En el primer escenario ya aparece el discurso urbano anunciando la existencia de una ciudad que ha comenzado a masificarse. A través de las emisiones de la radio, la capital logra su omnipresencia e introduce una imagen falsa.

Todos los signos que pertenecen al segundo escenario preparan y deforman la conciencia del inmigrante: encubren la ideología tras la máscara de la diversión y el progreso. Los personajes siguen un destino común: Dimas, Teodoro y Pura Guillén, Ramón Camacho y Luciano, habitarán los bordes de la ciudad y reproducirán, a su modo, el festín enajenante.

De allí, quizá, la mascarada, el aturdimiento alcohólico, la fe en el boxeo o el béisbol. Inmersos ya en el segundo escenario, se dedican a vivir la quimera urbana, a recrear los sueños pasados. Para ello recurren a lo festivo, porque, como indica Bajtín: "Es la fiesta la que, liberando de todo utilitarismo, de todo fin práctico, brinda los medios para entrar temporalmente a un universo utópico" $(1965,248)$.

Teodoro Guillén es el prototipo del personaje que busca tocar fondo. Impulsado por la frustración y la indigencia se ubica en las antípodas de los patiquines, los doctores del buen gusto. Representa así una especie de inversión de la frivolidad urbana: asume lo artificial de la miseria y vivirá dependiendo de toda la sordidez que lo circunda.

De pítcher estrella pasa a guapo de barrio y delincuente. Pero se apodera a su vez, no de un deportista como sucedio con él y con Ramón Camacho, sino de una prostituta, otro signo de lo artificial, desde el sobrenombre, "La Muñeca", hasta su función: el falso amor, el sexo instantáneo.

Todos continuarán entre la incertidumbre y la pobreza, rayando en la indigencia. Con la abyección como un signo maldito grabado para siempre en sus rostros: 
Si Pedro Luna quisiera cantar, jugarían a olvidarse de sus vidas en derrota, a creer que el vicio es algo bello y no lo que ellos saben de su miseria, de su hediondez, de su terrible y pálida podredumbre. Están allí solos, sin compradores. Si Pedro Luna quisiera cantar podrían creerse - solamente un rato- compradores de sí mismos (196-197).

En la práctica significante de Meneses, explica Douglas Bohórquez, se expresa "una misma obsesión de los límites, de lo abyecto" $(1986,136)$. Esto constituye una línea de trabajo y parte de una indagación en lo bajo humano; luego, de la interacción entre el personaje y el medio podemos extraer la proposición referencial, hacer un corte conceptual en el texto para observar la abyección como síndrome ideológico.

A la miseria material, vecina de la miseria humana, sólo se ofrece el viejo circo, el aturdimiento de la fiesta carnavalesca. Así se divierte (se evade) la nueva miseria urbana. En el ámbito de la fiesta desaparecen los primeros signos que levantaron en el escenario inicial. Ahora, ellos mismos manifiestan el discurso de la capital, son instrumentos de expresión al servicio de otra clase.

Detrás de estas páginas, Mr. Smith el de la Corporación, y los doctores-patiquines Luisito Diez, Julio Folgar y Pedrito Fajardo, mueven los hilos invisibles del ritmo.

Ahora son la ciudad, deben, por lo tanto, administrar los bienes, velar por el bienestar, ordenar y decidir. De allí, pues, que Teodoro administre y decida sobre "La Muñeca" en el mabil del zambo Cruz, o que Dimas y Luciano se enfrenten para decidir por Pura y que Ramón Camacho se transforme en un "caballero" y desaparezca luego, devorado por el sueño del boxeo, anhelo de progreso.

\section{MAR DE LEVA: EL CENTRO RECTOR}

\section{Las calles anónimas}

El espacio urbano referido en Mar de leva (1941) toma como punto de partida el de la ciudad de Caracas a finales de 1935: al igual que el objeto real está ubicado en los valles avileños, concentrado en las veinticinco manzanas del diseño colonial, con calles estrechas y esquinas identificadas; pero, a diferencia de éste, la ciudad textual posee dos núcleos básicos de acción: la casa y la plaza.

A excepción del Palacio de Gobierno, la estatua ecuestre del Libertador, la Catedral, algunas casas sin ubicación precisa $\mathrm{y}$, acaso, la sucinta relación de ciertos lugares universitarios, ninguna otra mención de edificios, construcciones o espacios, aparece para configurar su fisonomía.

Esto nos permite formular una hipótesis inicial: al parecer, a Fabbiani Ruiz no le interesó el reflejo, el dibujo exacto del objeto (Caracas), sino el conflicto que definiría al referente. Así, el espacio referencial habla a través de los discursos que lo complementan, emitidos por las voces del hablante básico y de los hablantes poéticos.

De allí, tal vez, la poca importancia fisonómica y la preeminencia de la ciudad invisible: las funciones del organismo urbano que se hace y deshace en el debate, en la confrontación interpersonajes y sus discursos ideológicos o ideologizados. 
De la ciudad visible se maneja cierta visión poética, expresada en imágenes que la presentan en algunos momentos como un ser vivo - cuerpo activo o dormido-y en otros como un objeto inanimado.

Después de los acontecimientos políticos, que en la realidad extratextual, soporte ficcional, corresponde a los sucesos inmediatos a la muerte de Juan Vicente Gómez, entre el desconcierto y la esperanza pública, "La ciudad entera hállase sumergida en un silencio espeso" (14). Luego: "Un silencio impenetrable (la) envuelve" (32).

La ciudad ha comenzado a prolongarse en extremidades que revelan los excesos del centro. Desde la periferia comienzan a observarse los rasgos del subdesarrollo. Ya no se exalta como la gran utopía. El centro administrativo está en crisis, se expande desesperado y muestra más miserias que riquezas.

La breve ciudad, referida como un cuerpo acuático alterado (mar de leva), existe alrededor de la Plaza Mayor, es decir, el centro: rostro diseñado en damero después de la fundación en el siglo XVI. Apenas comienza a desarrollarse: aún se observan techos rojos, pulperías, calles de adoquines.

Otros puntos de contacto o encuentro, además de la plaza y la universidad, lo constituyen las esquinas: "Tienda honda", "Balconcito" y "Gradillas", sirven para acercarnos al reflejo fisonómico de Caracas.

Las calles, en cambio, no indican dirección alguna, es decir, no señalan un destino concreto para el desplazamiento. Representan, para la sintaxis urbana, una suerte de calles ciegas: no tienen nombres, son sólo calles anónimas, fragmentos de espacios ficticios, intermedios, entre los centros semánticos de la ciudad textual.

Los núcleos básicos de acción, la casa y la plaza, son signos cuyos interpretantes, compuestos por elementos connotativos y denotativos, configuran dos polos de fuerza únicos: ambos son espacios abiertos, públicos. Uno indica el pasado y la permanencia de lo rural. Otro, el centro de la lucha cívica, el lugar del debate ciudadano, el ágora.

En la casa, los dormitorios tienen una enorme importancia, allí reinan las partes bajas del cuerpo. En la plaza crece el ideal, se realiza el intercambio de lo alto; desde ahí se determina el tiempo urbano: las horas de sueño y vigilia que deben cumplirse dentro y fuera de la casa: "La plaza Bolívar está cerca; sólo les falta una cuadra. El reloj de la Catedral envía por toda la ciudad sus campanadas graves y melancólicas" (55).

Durante la noche se mezclan sonidos de un cuerpo en transición entre lo rural y lo urbano. La paz de la aldea y la guerra de la ciudad en permanente interacción proponen un referente problematizado, estancando en la pugna civilizadora interna.

\section{El centro rector}

La permanencia de lo rural y los nuevos signos urbanos que comienzan a abrirse paso, tienen en Mar de leva sus representantes respectivos. La pugna "civilizadora" es conducida por los dos personajes principales inscritos en espacios muy específicos.

De este modo, podemos observar el limitado radio de acción (espacial e intelectual) de Nectario Lugo y la amplitud, en los mismos aspectos, de el Bachiller. Ambos ciudadanos son portadores de dos discursos encontrados, mas no excluyentes. 
Lugo, circunscrito a los espacios de intramuros, a la vieja casa de vecindad, es un signo activo de lo rural. El Bachiller, cuya vida transcurre a extramuros, en una especie de errancia citadina; es, por tanto, el emisor del nuevo discurso urbano.

Integran los centros básicos: Lugo, la casa y el Bachiller, la plaza. De allí que representan a su vez lo bajo y lo alto. El Bachiller es el ser pensante, impulsa las ideas políticas, su centro físico es la cabeza. Por el contrario, Nectario Lugo es el instinto sexual, el deseo reprimido, la embriaguez crónica y su centro físico es el sexo. Este personaje recuerda a los ciudadanos de Meneses y, como ellos, es inmigrante: proviene de los Valles del Tuy.

Espacios, personajes y discursos están en permanente interacción y, en lugar de excluirse, se incluyen aún en el rechazo: la casa está dentro del perímetro urbano y contiene, a su vez, a la ciudad: allí habita el Bachiller.

La convivencia tormentosa se repite, es la antigua interdependencia campo-ciudad sin la cual no podríamos explicarnos el proceso de formación urbana.

Ambos discursos se emiten, explícitamente, desde ángulos ideológicos diferentes. El de Lugo, en su confusión e incomprensión del proceso nacional bajo el caudillismo y su fantasma, refleja la falsa conciencia social.

El discurso de el Bachiller, fraguado en las aulas de clase, es el de la oposición política y de la reconstrucción cívica o, si se quiere, ciudadana. No obstante, los códigos que maneja hacen enunciados inflados de retórica estudiantil: "De temperamento ardido; odia la dictadura, instintivamente, porque apenas conoce sus orígenes económicos y sociales. Su condición revolucionaria es esencialmente romántica" (14-15).

Nectario Lugo es un personaje degradado. El dormitorio es su hábitat. El sexo, su emblema. Todo lo bajo, su señal distintiva. Es un individuo perdido en la ciudad, exponente de la enajenación urbana. Su vida concluye en la soledad y la incomunicación: "Sus labios articulan entrecortados monosílabos. Su mundo, desolado e incomprensible casi, se hace y deshace en aquel monólogo cortado, nervioso" (114).

Otros personajes muestran también las expresiones del rostro urbano. Las hijas de misia Petra la casera: Juana, María, Luisa y Adolfo, el hijo, manejan ciertos códigos que, para la época, eran de uso corriente en las ciudades latinoamericanas: "María dedica gran parte de su tiempo a la lectura de algún novelón sentimental e interminable". "En el recibo, Juana y María hablan y discuten sobre la última película de Libertad Lamarque" (18).

Otro elemento de vital importancia es la presencia de la multitud. Esos personajes anónimos, sin rostro, que pueblan los espacios públicos y asisten a actividades exclusivamente urbanas: "Con una gran lentitud la masa se deshace, repartiéndose entre las principales arterias que arrancan de la plaza Bolívar" (29).

Todos estos elementos van a dar testimonio, en primer lugar, de la existencia de un cuadro urbano mínimo y, en segundo lugar, del desarrollo del mismo. No obstante, los signos que van a configurar la fisiología de este organismo, se ubican en un plano secundario.

El centro semántico del texto lo constituye el discurso político alterno, opositor, que emite y representa el Bachiller. Esto, evidentemente, le otorga un significado político al espacio que nos ocupa. 
La ciudad, vista desde esta perspectiva, es el centro rector, el antiguo y eterno "puesto de mando". De allí la importancia de los espacios abiertos, del conflicto, del debate ideológico en la ciudad amordazada.

\section{LOS ALEGRES DESAHUCIADOS: UN CÍRCULO EXQUISITO Y DECADENTE}

\section{La ciudad vista desde arriba}

Nueve años después de Campeones aparece la primera habitación urbana: un edificio o "casa de apartamentos". Éste, unido a otros signos visibles de igual importancia, nos señala, de entrada, otro rostro urbano, como otro también será el tratamiento dado al referente:

En Los alegres desahuciados se encuentra un nuevo salto de la narrativa urbana. Las referencias algo eventuales, los desdibujos, la parcialidad de las muestras anteriores quedan superadas aquí, pues se trata de situar toda una narración en la ciudad pero haciendo al mismo tiempo narración de la ciudad. Ciertos resabios ultrapoéticos, cierta retórica y el innegable desequilibrio de planos dañan el conjunto, pero no impiden la excelencia de una caracterización diversificada, atenta a los individuos tanto como al contexto (Julio Miranda 1975, 175).

Aparecen, además, el primer dancing y la primera oficina de redacción de un periódico, centros donde se producen otros tipos de discursos que darán una configuración inédita al espacio referencial.

El apartamento donde habita uno de los personajes es un mirador para descubrir lo bajo urbano y humano: "Vivian caminó con manifiesto desgano hacia la ventana. Abajo se veían los techos rojos y acerados de las casas vecinas. Era risueño admirar las prosaicas intimidades que la humanidad exhibía en la trastienda de sus hogares" (11).

El edificio no tiene una ubicación precisa en la ciudad. E1 contraste con los techos rojos nos permite suponer su localización en el cuadro central, además, el exquisito personaje que allí habita jamás podría estar en la periferia.

En Los alegres desahuciados asistimos también al primer lugar nocturno de categoría. En las novelas anteriores predominan bodegas y bares de mala muerte. Los botiquines de La Guaira, el mabil del zambo Crucito (Campeones) y la pulpería (Mar de leva), son lugares donde usos y costumbres definen un ámbito rural. Estamos en presencia de un nuevo centro denominado dancing, donde han desaparecido los signos criollos o europeos, preferiblemente franceses, que predominaban hasta entonces.

En este nuevo centro nocturno desaparece también la intimidad. El intercambio se hace impersonal. Es un lugar masificado:

Aquello era un pandemónium. Las luces se apagaban y prendían. Nadie sabía la hora. Al que se le ocurriera preguntar la hora le enviarían a descifrar lascivias en los ojos desorbitados del Canciller que había vuelto en busca de la cálida mano del poeta Nro 35 (60). 
En calidad de pandemónium, más allá de la observación circunstancial, el dancing es, entonces, la "capital imaginaria del reino infernal": una ciudad dentro de otra, un caos dentro de otro. Es un signo exclusivamente urbano y más que urbano, cosmopolita. Lo internacional y lo universal se cruzan, conviven, se degradan: el canciller homosexual "busca la cálida mano" del poeta impersonal identificado con una cifra.

El otro signo urbano visible es la oficina de redacción del periódico donde trabaja Abigail. Ubicada en un lugar impreciso, como los edificios anteriores, la oficina contiene muebles inservibles y personajes grotescos. En este ambiente se reproducen los elementos que, entre otros, constituyen la red de relaciones de significación y procesos de comunicación donde se expresa el discurso ideológico que será consumido por los "estúpidos lectores".

Estos signos descubren un emporio en formación. El cuerpo, las ideas y las cosas, consideradas como mercancía, adquieren valor de cambio. La nueva urbe es el centro de un desmesurado consumo. El espacio se masifica. Ya se perfilan las calles como laberintos anónimos, se observan grandes edificios, transporte colectivo y una amplia "Avenida Central". Es mínima la relación con el objeto real: Caracas sólo se menciona en un par de oportunidades. Es sencillamente la ciudad, ésta o cualquier otra en la década del cuarenta.

\section{Un circulo exquisito y decadente}

En el centro del círculo de "alegres desahuciados" se localiza el concepto de ciudad que maneja Marino Palacio; se evidencia en el contraste establecido entre lo culto y lo vulgar.

Volvemos a lo alto en contraposición a lo bajo. Lo culto habita en el centro, el área metropolitana. Lo vulgar, las márgenes, los bordes. Lo culto se reúne en círculo, conforma una élite. Lo vulgar, lo inculto, es la masa amorfa, impersonal, de mal gusto:

Vivimos la era de la mediocridad. La era en que un anuncio de cótex llama más la atención que un fino y elegante ensayo de Alfonso Reyes o un cuento de Supervielle. Los millonarios adornan sus salas de baño con cuadros de Salvador Dalí y colocan ejemplares de "Ulises" para ser utilizados en sustitución del papel toilette (78).

Abigail es un ser escindido: perteneciente al círculo culto, exquisito, tiene su residencia en una pensión de mal gusto. De allí su fobia contra la indigencia y la irracionalidad animal. Tiene, quizá, más razones para desear la muerte o el vacío. Mientras Vivian, Zoilo y Lombardo se debaten en angustias existenciales y dramas metafísicos neorrománticos, Abigail padece angustias materiales.

No obstante, es miembro del círculo. Las referencias a Reyes, Supervielle y Joyce son elocuentes. Éstas, unidas a las menciones de Huxley y Lawrence, entre otros, señalan rasgos transculturales en la obra.

Es lícito establecer aquí una estrecha relación entre cultura y ciudad. La ciudad posee significado cultural, es un centro cultural. Esto, por supuesto, tiene que ver con el proceso transculturizador: "Nuestras literaturas son, fundamentalmente, ramas de las literaturas metropolitanas", afirma Cándido $(1977,347)$. Y aquellas metrópolis, además de centros administrativos y puestos de mando, ¿acaso no son centros culturales? 
Estos personajes son creadores y/o exponentes de cultura. Al contrario de los nuevos ciudadanos de Campeones, Vivian, Abigail, Lombardo y Zoilo, desarrollan parte del discurso de la ciudad; hacen, en cierto grado, la fisiología del cuerpo urbano: manejan lenguajes alternos (poesía) y, también, otros (periodismo) que repiten los enunciados oficiales.

Son, ante todo, intelectuales, miembros de la ciudad letrada. Jóvenes de postguerra que importan el desaliento, la desesperanza, la sensación de vacío que dejaron las batallas en las metrópolis europeas después de 1945.

De allí, quizá, el desasosiego, lo absurdo, el caos y la soledad que los atormenta, sensaciones todas que se convertirán en significantes de la vida urbana, indicios de lo malsano, de lo impuro del nuevo conglomerado: "Para Vivian, la existencia no pasaba de ser una ridícula escena de una comedia escrita sin habilidad" (11).

Desde esta perspectiva, el círculo exquisito y decadente constituye lo urbano. No obstante, la ciudad masificada, plural, se les escapa de las manos. De allí la desazón, lo desahuciado o la caída lenta, simultánea: "Somos los alegres desahuciados. Creemos sintetizar una maravillosa condición, creemos formar parte de una secta de predestinados y no somos más que niños encantadores, ardientes sentidores de lo universalmente estético" (85).

El referente urbano extraido del discurso de estos personajes, descubre la imposibilidad de concebir a la ciudad como "creación artística". Ética y estética son ideales excluidos del aparato productor, transformados en el discurso alterno de los medios, absorbidos por la demagogia generalizada denominada "cultura de masas".

El círculo se cierra. Hereda el dandismo, el dilettantismo, la decadencia de finales del siglo XIX, el vacío existencial contemporáneo y, paralelamente a la razón, se centran en el cuerpo, antecediendo quizá a las tendencias del body art; cerrándose, en fin, en una especie de solipcismo narcisista.

\section{CONCLUSIONES}

La división en cuerpo y función nos ha servido para conocer el objeto real y determinar el referente. La ciudad visible (fisonomía) y la ciudad invisible (fisiología), nos permitieron ubicar el carácter referencial de la ciudad textual.

Desde el cuerpo se establece una relación mínima con el objeto, podemos hacer un balance entre las presencias y ausencias textuales y contextuales para observar el grado de "similitud". Desde su funcionamiento se aprecia el carácter autónomo, textual - sin olvidar las proposiciones interdiscursivas-y se obtiene el significado de la ciudad textual.

De este modo, en Campeones observamos la construcción fisonómica bajo el título "Primeros signos de la urbanización". Examinamos la fisiología, cuando ya los personajes se encuentran en el segundo escenario, bajo el título "Fiesta y abyección".

En Mar de leva, "Las calles anónimas" reflejan, en cierto modo, el cuadro central caraqueño a finales de 1935. En "El centro rector" se señala el tradicional poder de la ciudad como capital.

En Los alegres desahuciados, finalmente, justo en su primera parte: "La ciudad vista desde arriba", se señala un hallazgo; el primer edificio residencial o "Casa de apartamentos", 
elemento que cambia radicalmente la visión urbana del personaje. En la segunda, entonces, se define la ciudad desde la proposiciones del hablante básico como "Un círculo exquisito y decadente".

En la novela de Meneses la ciudad es, en primer lugar, una utopía y, en segundo, una quimera. Es el ámbito de la fiesta y la abyección: el lugar de la inversión carnavalesca y el escenario del vicio.

En Fabbiani Ruiz, la ciudad es el centro que rige el destino del país, el espacio de las decisiones. Es el antiguo y eterno "puesto de mando".

En Marino Palacio surge la ciudad decididamente masificada. Es un gran centro de consumo y un centro cultural donde la masa consume lo subcultural —el discurso populista- y la élite lo más sublime del arte. Aquí, la ciudad podría representarse en forma de anillos que se contienen unos a otros. En el del centro, por supuesto, hallaríamos el "círculo exquisito y decadente".

Las novelas estudiadas son antecedentes ineludibles de la narrativa de referente urbano. Las obras desarrolladas a posteriori, siguiendo esta dirección, harán la llamada "narrativa urbana". Esta tendencia cobra fuerza a partir de los primeros años del período 1960-1970 y es impulsada por autores como Osvaldo Trejo, Salvador Garmendia, Vicente Ibarra, Adriano González León, Renato Rodríguez, Gustavo Luis Carrera, Luis Britto García, José Balza, Carlos Noguera y Eduardo Liendo, entre otros, de cuyas obras nos ocuparemos luego de concluir un estudio que hemos comenzado como continuación de éste, el cual se centra, naturalmente, en la indagación de la ciudad textual en la novelística de la década de los cincuenta.

\section{REFERENCIAS BIBLIOGRÁFICAS}

Bajtín, Mijail. La cultura popular en la Edad Media y Renacimiento. Barcelona: Barral, 1974.

Bohórquez, Douglas. Teoría semiológica del texto literario. Una lectura de Guillermo Meneses. Mérida: ULA, 1986.

Cándido, Antonio. América Latina en su literatura. César Fernández Moreno, compilador. México: Siglo Veintiuno, 1977.

Eco, Umberto. Tratado de semiótica general. Barcelona: Nueva Imagen-Lumen, 1978. Fabbiani Ruiz, José. Mar de leva (1941). Caracas: Monte Ávila Editores, 1972.

Lewis, Thomas. "Hacia una teoría del referente literario". Texto Crítico. México, 1980. 3-31.

Marino Palacio, Andrés. Los alegres desahuciados. Editorial Bolívar, 1948.

Meneses, Guillermo. Campeones. Cinco Novelas (1939). Caracas: Monte Ávila Editores, 1972.

Miranda, Julio. Proceso a la narrativa venezolana. Caracas: UCV, 1975.

Rama, Ángel. La ciudad letrada. Montevideo: Fundación Internacional Ángel Rama, 1984. 
